\title{
Homoclinic solutions for a kind of prescribed mean curvature Duffing-type equation
}

Zaitao Liang ${ }^{1 *}$ and Shiping $\mathrm{Lu}^{1,2}$

"Correspondence:

liangzaitao@sina.cn

1 Department of Mathematics,

Anhui Normal University, Wuhu,

241000, China

Full list of author information is

available at the end of the article

\begin{abstract}
In this paper, by using Mawhin's continuation theorem and some analysis methods, the existence of a set with $2 k T$-periodic solutions for a kind of prescribed mean curvature Duffing-type equation is studied, and then a homoclinic solution is obtained as a limit of a certain subsequence of the above set.
\end{abstract}

Keywords: homoclinic solution; continuation theorem; prescribed mean curvature

\section{Introduction}

In this paper, we investigate the existence of homoclinic solutions for a class of prescribed mean curvature Duffing-type equations

$$
\left(\frac{u^{\prime}(t)}{\sqrt{1+\left(u^{\prime}(t)\right)^{2}}}\right)^{\prime}+c u^{\prime}(t)+f(u(t))=p(t)
$$

where $f \in C^{1}(R, R), p \in C(R, R), c>0$ is a given constant.

As is well known, a solution $u(t)$ of Eq. (1.1) is named homoclinic (to 0$)$ if $u(t) \rightarrow 0$ and $u^{\prime}(t) \rightarrow 0$ as $|t| \rightarrow+\infty$. In addition, if $u \neq 0$, then $u$ is called a nontrivial homoclinic solution.

A prescribed mean curvature equation and its modified forms derived from differential geometry and physics have been widely researched in many papers. For example, combustible gas dynamics [1-3]. In recent years, many papers about periodic solutions for the prescribed mean curvature equation and its modified forms have appeared. For example, by using an approach based on the Leray-Schauder degree, Benevieri et al. in [4] studied the periodic solutions for nonlinear equations with mean curvature-like operators. And in [5] Benevieri et al. extended the results obtained in [4] to the $N$-dimensional case.

Recently, Feng in [6] studied the periodic solutions for a prescribed mean curvature Liénard equation with deviating argument as follows:

$$
\left(\frac{x^{\prime}(t)}{\sqrt{1+\left(x^{\prime}(t)\right)^{2}}}\right)^{\prime}+f(x(t)) x^{\prime}(t)+g(t, x(t-\tau(t)))=e(t)
$$


where $\tau, e \in C(R, R)$ are $T$-periodic, and $g \in C(R \times R, R)$ are $T$-periodic in the first argument, $T>0$ is a constant. Through the transformation, (1.2) is equivalent to the system

$$
\left\{\begin{array}{l}
x_{1}^{\prime}(t)=\frac{x_{2}(t)}{\sqrt{1-x_{2}^{2}(t)}}, \\
x_{2}^{\prime}(t)=-f\left(x_{1}(t)\right) \frac{x_{2}(t)}{\sqrt{1-x_{2}^{2}(t)}}-g\left(t, x_{1}(t-\tau(t))\right)+e(t) .
\end{array}\right.
$$

By using Mawhin's continuation theorem in the coincidence degree theory, and given some sufficient conditions, the authors obtained that Eq. (1.2) has at least one periodic solution. From the first equation of (1.3), we can see that a $T$-periodic function $x_{2}(t)$ must satisfy $\max _{t \in[0, T]}\left|x_{2}(t)\right|<1$, hence the open and bounded set $\Omega$ of Mawhin's continuation theorem must satisfy $\Omega \subset\left\{\left(x_{1}, x_{2}\right)^{T} \in X:\left|x_{1}\right|_{\infty}<d,\left|x_{2}\right|_{\infty}<\rho<1\right\}$. But in [6], the authors obtained $\Omega=\left\{\left(x_{1}, x_{2}\right)^{T} \in X:\left|x_{1}\right|_{\infty}<N_{1},\left|x_{2}\right|_{\infty}<N_{2}\right\}$, there is no proof about $N_{2}<1$. A similar problem also occurred in [7] and [8].

In order to solve this problem, we study the existence of homoclinic solutions for prescribed mean curvature Duffing-type equation corresponding theory, which has not been investigated till now to the best of our knowledge. In this paper, like in the work of Rabinowitz in [9], Lzydorek and Janczewska in [10], Tang and Xiao in [11] and Lu in [12], the existence of a homoclinic solution for Eq. (1.1) is obtained as a limit of a certain sequence of $2 k T$-periodic solutions for the following equation:

$$
\left(\frac{u^{\prime}(t)}{\sqrt{1+\left(u^{\prime}(t)\right)^{2}}}\right)^{\prime}+c u^{\prime}(t)+f(u(t))=p_{k}(t)
$$

where $k \in N, p_{k}: R \rightarrow R$ is a $2 k T$-periodic function such that

$$
p_{k}(t)= \begin{cases}p(t), & t \in\left[-k T, k T-\varepsilon_{0}\right), \\ p\left(k T-\varepsilon_{0}\right)+\frac{p(-k T)-p\left(k T-\varepsilon_{0}\right)}{\varepsilon_{0}}\left(t-k T+\varepsilon_{0}\right), & t \in\left[k T-\varepsilon_{0}, k T\right],\end{cases}
$$

$\varepsilon_{0} \in(0, T)$ is a constant independent of $k$. The existence of $2 k T$-periodic solutions to Eq. (1.4) is obtained by using Mawhin's continuation theorem [13]. We obtain $\Omega=\left\{v=(x, y)^{T} \in\right.$ $\left.X_{k},|x|_{0}<\rho_{0}+\beta,|y|_{0}<\frac{\rho_{1}+1}{2}\right\}$, where $\rho_{1}<1$, by which we overcome the problem in [6-8]. The rest of this paper organized as follows. In Section 2, we provide some necessary background definitions and lemmas. In Section 3, we give the results that we have obtained.

\section{Preliminary}

In order to use Mawhin's continuation theorem [13], we first recall it.

Let $X$ and $Y$ be two Banach spaces with norms $\|\cdot\|_{X},\|\cdot\|_{Y}$, respectively. A linear operator $L: D(L) \subset X \rightarrow Y$ is said to be a Fredholm operator of index zero provided that

(a) $\operatorname{Im} L$ is a closed subset of $Y$,

(b) $\operatorname{dim} \operatorname{Ker} L=\operatorname{codim} \operatorname{Im} L<\infty$.

Let $N: \Omega \subset X \rightarrow Y$ be a continuous operator, $N$ is said to be $L$-compact and continuous in $\bar{\Omega}$ provided that

(c) $K_{p}(I-Q) N(\bar{\Omega})$ is a relative compact set of $X$,

(d) $Q N(\bar{\Omega})$ is a bounded set of $Y$, 
where we define $X_{1}=\operatorname{Ker} L, Y_{2}=\operatorname{Im} L$. Then we have the decompositions $X=X_{1} \oplus X_{2}$, $Y=Y_{1} \oplus Y_{2}$. Let $P: X \rightarrow X_{1}, Q: Y \rightarrow Y_{1}$ be continuous linear projectors (meaning $P^{2}=P$ and $\left.Q^{2}=Q\right)$, and $K_{p}=\left.L\right|_{\operatorname{Ker} P \cap D(L)} ^{-1}$.

Lemma 2.1 [13] Let $X$ and $Y$ be two Banach spaces with norms $\|\cdot\|_{X},\|\cdot\|_{Y}$, respectively, and let $\Omega$ be an open and bounded set of $X$. Let $L: D(L) \subset X \rightarrow Y$ be a Fredholm operator of index zero, and let $N: \bar{\Omega} \subset X \rightarrow Y$ be L-compact on $\bar{\Omega}$. In addition, if the following conditions hold:

(H1) $L v \neq \lambda N v, \forall(v, \lambda) \in \partial \Omega \times(0,1)$;

(H2) $Q N v \neq 0, \forall v \in \operatorname{Ker} L \cap \partial \Omega$;

(H3) $\operatorname{deg}\{J Q N, \Omega \cap \operatorname{Ker} L, 0\} \neq 0$, where $J: \operatorname{Im} Q \rightarrow \operatorname{Ker} L$ is just any homeomorphism, then $L v=N v$ has at least one solution in $D(L) \cap \bar{\Omega}$.

Lemma 2.2 If $u: R \rightarrow R$ is continuously differentiable on $R, a>0, \mu>1$ and $p>1$ are constants, then for every $t \in R$, the following inequality holds:

$$
|u(t)| \leq(2 a)^{-\frac{1}{\mu}}\left(\int_{t-a}^{t+a}|u(s)|^{\mu} d s\right)^{\frac{1}{\mu}}+a(2 a)^{-\frac{1}{p}}\left(\int_{t-a}^{t+a}\left|u^{\prime}(s)\right|^{p} d s\right)^{\frac{1}{p}} .
$$

This lemma is Corollary 2.1 in [11].

Lemma 2.3 [11] Let $u_{k} \in C_{2 k T}^{2}$ be a $2 k T$-periodic function for each $k \in \mathbf{N}$ with

$$
\left|u_{k}\right|_{0} \leq A_{0}, \quad\left|u_{k}^{\prime}\right|_{0} \leq A_{1}, \quad\left|u_{k}^{\prime \prime}\right|_{0} \leq A_{2},
$$

where $A_{0}, A_{1}$ and $A_{2}$ are constants independent of $k \in \mathbf{N}$. Then there exists a function $u_{0} \in$ $C^{1}(R, R)$ such that for each interval $[c, d] \subset R$, there is a subsequence $\left\{u_{k_{j}}\right\}$ of $\left\{u_{k}\right\}_{k \in \mathbf{N}}$ with $u_{k_{j}}^{\prime}(t) \rightarrow u_{0}^{\prime}(t)$ uniformly on $[c, d]$.

Let $u(t)=x(t)$, then system (1.4) is equivalent to the system

$$
\left\{\begin{array}{l}
x^{\prime}(t)=\varphi(y(t))=\frac{y(t)}{\sqrt{1-y^{2}(t)}} \\
y^{\prime}(t)=-c \varphi(y(t))-f(x(t))+p_{k}(t) .
\end{array}\right.
$$

Let $X_{k}=\left\{v=(x(t), y(t))^{T} \in C\left(R, R^{2}\right), v(t)=v(t+2 k T)\right\}$ and $Y_{k}=\left\{v=(x(t), y(t))^{T} \in C(R\right.$, $\left.\left.R^{2}\right), v(t)=v(t+2 k T)\right\}$, where the norm $\|v\|=\max \left\{|x|_{0},|y|_{0}\right\}$ with $|x|_{0}=\max _{t \in[0,2 k T]}|x(t)|$ and $|y|_{0}=\max _{t \in[0,2 k T]}|y(t)|$. It is obvious that $X_{k}$ and $Y_{k}$ are Banach spaces.

Now we define the operator

$$
L: D(L) \subset X_{k} \rightarrow Y_{k}, \quad L v=v^{\prime}=\left(x^{\prime}(t), y^{\prime}(t)\right)^{T},
$$

where $D(L)=\left\{v \mid v=(x(t), y(t))^{T} \in C^{1}\left(R, R^{2}\right), v(t)=v(t+2 k T)\right\}$.

Let $Z_{k}=\left\{v \mid v=(x(t), y(t))^{T} \in C^{1}(R, R \times(-1,1)), v(t)=v(t+2 k T)\right\}$, define a nonlinear operator $N: \bar{\Omega} \rightarrow Y_{k}$ as follows:

$$
N v=\left(\frac{y(t)}{\sqrt{1-y^{2}(t)}},-c \varphi(y(t))-f(x(t))+p_{k}(t)\right)^{T},
$$


where $\bar{\Omega} \subset Z_{k} \subset X_{k}$ and $\Omega$ is an open and bounded set. Then problem (2.1) can be written as $L v=N v$ in $\bar{\Omega}$. We know

$$
\operatorname{Ker} L=\left\{v \mid v \in X_{k}, v^{\prime}=\left(x^{\prime}(t), y^{\prime}(t)\right)^{T}=(0,0)^{T}\right\}
$$

then $x^{\prime}(t)=0, y^{\prime}(t)=0$, obviously $x \in R, y \in R$, thus $\operatorname{Ker} L=R^{2}$, and it is also easy to prove that $\operatorname{Im} L=\left\{z \in Y_{k}, \int_{0}^{2 k T} z(s) d s=0\right\}$. So, $L$ is a Fredholm operator of index zero.

Let

$$
\begin{aligned}
& P: X_{k} \rightarrow \operatorname{Ker} L, \quad P v=\frac{1}{2 k T} \int_{0}^{2 k T} v(s) d s, \\
& Q: Y_{k} \rightarrow \operatorname{Im} Q, \quad Q z=\frac{1}{2 k T} \int_{0}^{2 k T} z(s) d s .
\end{aligned}
$$

Let $K_{p}=\left.L\right|_{\mathrm{Ker} p \cap D(L)} ^{-1}$, then it is easy to see that

$$
\left(K_{p} z\right)(t)=\int_{0}^{2 k T} G_{k}(t, s) z(s) d s
$$

where

$$
G(t, s)= \begin{cases}\frac{s-2 k T}{2 k T}, & 0 \leq t \leq s \\ \frac{s}{2 k T}, & s \leq t \leq 2 k T\end{cases}
$$

For all $\Omega$ such that $\bar{\Omega} \subset\left(X_{k} \cap Z_{k}\right) \subset X_{k}$, we have $K_{p}(I-Q) N(\bar{\Omega})$ is a relative compact set of $X_{k}, Q N(\bar{\Omega})$ is a bounded set of $Y_{k}$, so the operator $N$ is $L$-compact in $\bar{\Omega}$.

\section{Main results}

For the sake of convenience, we list the following conditions.

$\left(\mathrm{A}_{1}\right)$ There exist constants $m_{0}>0, p>1$ such that $x f(x) \leq-m_{0} x^{p}$ and $f^{\prime}(x)<0, \forall x \in R$.

$\left(\mathrm{A}_{2}\right) p \in C(R, R)$ is a bounded function with $p(t) \neq 0$ and $B:=\max \left\{\left(\int_{R}|p(t)|^{2} d t\right)^{\frac{1}{2}}\right.$, $\left.\left(\int_{R}|p(t)|^{q} d t\right)^{\frac{1}{q}}\right\}+\sup _{t \in R}|p(t)|<+\infty$, where $\frac{1}{p}+\frac{1}{q}=1$.

Remark 3.1 From (1.5) we see that $\left|p_{k}(t)\right| \leq \sup _{t \in R}|p(t)|$. So, if assumption $\left(\mathrm{A}_{2}\right)$ holds, for each $k \in \mathbf{N},\left(\int_{-k T}^{k T}\left|p_{k}(t)\right|^{2} d t\right)^{\frac{1}{2}}<B$ and $\left(\int_{-k T}^{k T}\left|p_{k}(t)\right|^{q} d t\right)^{\frac{1}{q}}<B$.

In order to study the existence of $2 k T$-periodic solutions to system (2.1), we firstly study some properties of all possible $2 k T$-periodic solutions to the following system:

$$
\left\{\begin{array}{l}
x^{\prime}(t)=\lambda \varphi(y(t))=\lambda \frac{y(t)}{\sqrt{1-y^{2}(t)}}, \\
y^{\prime}(t)=-\lambda c \varphi(y(t))-\lambda f(x(t))+\lambda p_{k}(t), \quad \lambda \in(0,1]
\end{array}\right.
$$

where $\left(x_{k}, y_{k}\right)^{T} \in Z_{k} \subset X_{k}$. For each $k \in \mathbf{N}$ and all $\lambda \in(0,1]$, let $\Sigma$ represent the set of all the $2 k T$-periodic solutions to the above system. 
Theorem 3.1 Assume that conditions $\left(\mathrm{A}_{1}\right)-\left(\mathrm{A}_{2}\right)$ hold, $c>0$ and $B^{\frac{p}{2 p-2}}+T B m_{0}^{\frac{1}{2 p-2}}<$ $\sqrt{2 T} m_{0}^{\frac{1}{2 p-2}}$, then for each $k \in \mathbf{N}$, if $(x, y)^{T} \in \Sigma$, there are positive constants $\rho_{0}, \rho_{1}, \rho_{2}$ and $\rho_{3}$ which are independent of $k$ and $\lambda$ such that

$$
|x|_{0} \leq \rho_{0}, \quad|y|_{0} \leq \rho_{1}<1, \quad\left|x^{\prime}\right|_{0} \leq \rho_{2}, \quad\left|y^{\prime}\right|_{0} \leq \rho_{3} .
$$

Proof For each $k \in \mathbf{N}$, if $(x, y)^{T} \in \Sigma$, it must satisfy

$$
\left\{\begin{array}{l}
x^{\prime}(t)=\lambda \varphi(y(t))=\lambda \frac{y(t)}{\sqrt{1-y^{2}(t)}}, \\
y^{\prime}(t)=-\lambda c \varphi(y(t))-\lambda f(x(t))+\lambda p_{k}(t), \quad \lambda \in(0,1] .
\end{array}\right.
$$

The first equation of the above system is equivalent to the equation

$$
\left\{\begin{array}{l}
x^{\prime}(t)=\lambda \varphi(y(t))=\lambda \frac{y(t)}{\sqrt{1-y^{2}(t)}}, \\
y^{\prime}(t)=-c x^{\prime}(t)-\lambda f(x(t))+\lambda p_{k}(t), \quad \lambda \in(0,1] .
\end{array}\right.
$$

Multiplying the first equation of (3.1) by $y^{\prime}(t)$ and integrating from $-k T$ to $k T$, we have

$$
\int_{-k T}^{k T} y^{\prime}(t) x^{\prime}(t) d t=\int_{-k T}^{k T} y^{\prime}(t) \lambda \varphi(y(t)) d t=\int_{-k T}^{k T} \lambda \varphi(y(t)) d y(t)=0,
$$

it follows from the second equation of (3.1) that

$$
\begin{aligned}
c \int_{-k T}^{k T}\left(x^{\prime}(t)\right)^{2} d t & =-\lambda \int_{-k T}^{k T} f(x(t)) x^{\prime}(t) d t+\lambda \int_{-k T}^{k T} p_{k}(t) x^{\prime}(t) d t \\
& =\lambda \int_{-k T}^{k T} p_{k}(t) x^{\prime}(t) d t \leq \int_{-k T}^{k T}\left|p_{k}(t)\right|\left|x^{\prime}(t)\right| d t .
\end{aligned}
$$

By using Holder's inequality to (3.2), we obtain

$$
c\left\|x^{\prime}\right\|_{2}^{2} \leq\left(\int_{-k T}^{k T}\left|p_{k}(t)\right|^{2} d t\right)^{\frac{1}{2}}\left(\int_{-k T}^{k T}\left|x^{\prime}(t)\right|^{2} d t\right)^{\frac{1}{2}}=\left\|x^{\prime}\right\|_{2}\left\|p_{k}\right\|_{2},
$$

which implies that

$$
\left\|x^{\prime}\right\|_{2} \leq \frac{B}{c}=d_{0} .
$$

Multiplying the second equation of (3.1) by $x(t)$ and integrating from $-k T$ to $k T$, we have

$$
-\lambda \int_{-k T}^{k T} \frac{y^{2}(t)}{\sqrt{1-y^{2}(t)}} d t=-\lambda \int_{-k T}^{k T} x(t) f(x(t))+x(t) p_{k}(t) d t,
$$

i.e.,

$$
\int_{-k T}^{k T} \frac{y^{2}(t)}{\sqrt{1-y^{2}(t)}}+x(t) f(x(t)) d t=-\int_{-k T}^{k T} x(t) p_{k}(t) d t \leq \int_{-k T}^{k T}|x(t)|\left|p_{k}(t)\right| d t .
$$


Since $\frac{y^{2}(t)}{\sqrt{1-y^{2}(t)}} \geq y^{2}(t)$, and combining (3.4) with $\left(\mathrm{A}_{1}\right)$, we get

$$
\|y\|_{2}^{2}+m_{0}\|x\|_{p}^{p} \leq \int_{-k T}^{k T}|x(t)|\left|p_{k}(t)\right| d t
$$

by using Holder's inequality to the above inequality, we obtain

$$
\|y\|_{2}^{2}+m_{0}\|x\|_{p}^{p} \leq\left\|p_{k}\right\|_{q}\|x\|_{p}
$$

which implies that

$$
m_{0}\|x\|_{p}^{p} \leq\left\|p_{k}\right\|_{q}\|x\|_{p}
$$

and

$$
\|y\|_{2}^{2} \leq\left\|p_{k}\right\|_{q}\|x\|_{p}
$$

So, from Remark 3.1 and (3.5), we can conclude that

$$
\|x\|_{p} \leq\left(\frac{B}{m_{0}}\right)^{\frac{1}{p-1}}:=d_{1} .
$$

Thus, by using Lemma 2.2 for all $t \in[-k T, k T]$, we get

$$
\begin{aligned}
|x(t)| & \leq(2 T)^{-\frac{1}{p}}\left(\int_{t-T}^{t+T}|x(s)|^{p} d s\right)^{\frac{1}{p}}+T(2 T)^{-\frac{1}{2}}\left(\int_{t-T}^{t+T}\left|x^{\prime}(s)\right|^{2} d s\right)^{\frac{1}{p}} \\
& \leq(2 T)^{-\frac{1}{p}}\left(\int_{t-k T}^{t+k T}|x(s)|^{p} d s\right)^{\frac{1}{p}}+T(2 T)^{-\frac{1}{2}}\left(\int_{t-k T}^{t+k T}\left|x^{\prime}(s)\right|^{2} d s\right)^{\frac{1}{2}} \\
& =(2 T)^{-\frac{1}{p}}\left(\int_{-k T}^{k T}|x(s)|^{p} d s\right)^{\frac{1}{p}}+T(2 T)^{-\frac{1}{2}}\left(\int_{-k T}^{k T}\left|x^{\prime}(s)\right|^{2} d s\right)^{\frac{1}{2}} .
\end{aligned}
$$

From (3.3), (3.7) and (3.8), we obtain

$$
|x|_{0}=\max _{t \in[-k T, k T]}|x(t)| \leq(2 T)^{-\frac{1}{p}} d_{1}+\sqrt{\frac{T}{2}} d_{0}:=\rho_{0} .
$$

Obviously, $\rho_{0}$ is a constant which is independent of $k$ and $\lambda$. From Remark 3.1, (3.6) and (3.7), we obtain

$$
\|y\|_{2} \leq B^{\frac{1}{2}}\left(\frac{B}{m_{0}}\right)^{\frac{1}{2 p-2}}:=d_{2} .
$$

Multiplying the second equation of (3.1) by $y^{\prime}(t)$ and integrating from $-k T$ to $k T$, we have

$$
\begin{aligned}
\int_{-k T}^{k T}\left(y^{\prime}(t)\right)^{2} d t & =-c \int_{-k T}^{k T} x^{\prime}(t) y^{\prime}(t) d t-\int_{-k T}^{k T} \lambda y^{\prime}(t) f(x(t)) d t+\int_{-k T}^{k T} \lambda y^{\prime}(t) p_{k}(t) d t \\
& =\int_{-k T}^{k T} \lambda^{2} f^{\prime}(x(t)) \frac{y^{2}(t)}{\sqrt{1-y^{2}(t)}} d t+\int_{-k T}^{k T} \lambda y^{\prime}(t) p_{k}(t) d t
\end{aligned}
$$


From $\left(\mathrm{A}_{1}\right)$, we know that

$$
\int_{-k T}^{k T}\left(y^{\prime}(t)\right)^{2} d t \leq \int_{-k T}^{k T}\left|y^{\prime}(t)\right|\left|p_{k}(t)\right| d t
$$

by using Holder's inequality to the above inequality, we obtain

$$
\left\|y^{\prime}\right\|_{2}^{2} \leq\left\|p_{k}\right\|_{2}\left\|y^{\prime}\right\|_{2}
$$

from Remark 3.1, we can conclude that

$$
\left\|y^{\prime}\right\|_{2} \leq B:=d_{3}
$$

In a similar way to (3.9), we get

$$
|y|_{0}=\max _{t \in[-k T, k T]}|y(t)| \leq(2 T)^{-\frac{1}{2}} d_{2}+\sqrt{\frac{T}{2}} d_{3}=\frac{B^{\frac{p}{2 p-2}}+T B m_{0}^{\frac{1}{2 p-2}}}{\sqrt{2 T} m_{0}^{\frac{1}{2 p-2}}} .
$$

Since $B^{\frac{p}{2 p-2}}+T B m_{0}^{\frac{1}{2 p-2}}<\sqrt{2 T} m_{0}^{\frac{1}{2 p-2}}$, we have

$$
|y|_{0} \leq \frac{B^{\frac{p}{2 p-2}}+T B m_{0}^{\frac{1}{2 p-2}}}{\sqrt{2 T} m_{0}^{\frac{1}{2 p-2}}}:=\rho_{1}<1
$$

Obviously, $\rho_{1}$ is a constant which is independent of $k$ and $\lambda$. Let $f_{\rho}=\max _{|x| \leq \rho_{0}}|f(x)|$. From (3.1) we have

$$
\left|x^{\prime}(t)\right|_{0} \leq \max _{t \in[-k T, k T]} \frac{|y(t)|}{\sqrt{1-y^{2}(t)}} \leq \frac{\rho_{1}}{1-\rho_{1}^{2}}:=\rho_{2} .
$$

Obviously, $\rho_{2}$ is a constant which is independent of $k$ and $\lambda$, and

$$
\left|y^{\prime}(t)\right|_{0} \leq c\left|x^{\prime}(t)\right|+|f(x(t))|+\left|p_{k}(t)\right| \leq c \rho_{2}+f_{\rho}+B:=\rho_{3} \text {. }
$$

Obviously, $\rho_{3}$ is a constant which is independent of $k$ and $\lambda$. From (3.9), (3.12), (3.13) and (3.14), we know $\rho_{0}, \rho_{1}, \rho_{2}$ and $\rho_{3}$ are constants independent of $k$ and $\lambda$. Hence the conclusion of Theorem 3.1 holds.

Theorem 3.2 Assume that the conditions of Theorem 3.1 are satisfied. Then, for each $k \in$ $N$, system (2.1) has at least one $2 k T$-periodic solution $\left(x_{k}(t), y_{k}(t)\right)^{T}$ in $\Sigma \subset X_{k}$ such that

$$
\left|x_{k}\right|_{0} \leq \rho_{0}, \quad\left|y_{k}\right|_{0} \leq \rho_{1}<1, \quad\left|x_{k}^{\prime}\right|_{0} \leq \rho_{2}, \quad\left|y_{k}^{\prime}\right|_{0} \leq \rho_{3},
$$

where $\rho_{0}, \rho_{1}, \rho_{2}, \rho_{3}$ are constants defined by Theorem 3.1.

Proof In order to use Lemma 2.1, for each $k \in N$, we consider the following system:

$$
\left\{\begin{array}{l}
x^{\prime}(t)=\lambda \varphi(y(t))=\lambda \frac{y(t)}{\sqrt{1-y^{2}(t)}} \\
y^{\prime}(t)=-\lambda c \varphi(y(t))-\lambda f(x(t))+\lambda p_{k}(t), \quad \lambda \in(0,1),
\end{array}\right.
$$


where $y(t)=\frac{\frac{1}{\lambda} x^{\prime}(t)}{\sqrt{1+\left(\frac{1}{\lambda} x^{\prime}(t)\right)^{2}}}$. Let $\Omega_{1} \subset X_{k}$ represent the set of all the $2 k T$-periodic solutions of system (3.15). Since $(0,1) \subset(0,1]$, then $\Omega_{1} \subset \Sigma$, where $\Sigma$ is defined by Theorem 3.1. If $(x, y)^{T} \in \Omega_{1}$, by using Theorem 3.1, we get

$$
|x|_{0} \leq \rho_{0}, \quad|y|_{0} \leq \rho_{1}<1
$$

Let $\Omega_{2}=\left\{v=(x, y)^{T} \in \operatorname{Ker} L, Q N v=0\right\}$. If $(x, y)^{T} \in \Omega_{2}$, then $(x, y)^{T}=\left(a_{1}, a_{2}\right)^{T} \in R^{2}$ (constant vector), we see that

$$
\left\{\begin{array}{l}
\int_{-k T}^{k T} \frac{a_{2}}{\sqrt{1-a_{2}^{2}}} d t=0, \\
\int_{-k T}^{k T}-c \frac{a_{2}}{\sqrt{1-a_{2}^{2}}}-f\left(a_{1}\right)+p_{k}(t) d t=0,
\end{array}\right.
$$

i.e.,

$$
\left\{\begin{array}{l}
a_{2}=0 \\
\int_{-k T}^{k T}-f\left(a_{1}\right)+p_{k}(t) d t=0
\end{array}\right.
$$

Multiplying the second equation of (3.16) by $a_{1}$, we have

$$
2 k T m_{0}\left|a_{1}\right|^{p} \leq \int_{-k T}^{k T}\left|a_{1}\right|\left|p_{k}(t)\right| d t \leq \sqrt{2 k T}\left|a_{1}\right| B,
$$

thus

$$
\left|a_{1}\right| \leq\left(\frac{B}{\sqrt{2 k T} m_{0}}\right)^{\frac{1}{p-1}} \leq\left(\frac{B}{\sqrt{2 T} m_{0}}\right)^{\frac{1}{p-1}}:=\beta .
$$

Now, if we set $\Omega=\left\{v=(x, y)^{T} \in X_{k},|x|_{0}<\rho_{0}+\beta,|y|_{0}<\frac{\rho_{1}+1}{2}\right\}$, it is easy to see that $\frac{\rho_{1}+1}{2}<1$, then $\Omega \supset \Omega_{1} \cup \Omega_{2}$. So, condition (H1) and condition (H2) of Lemma 2.1 are satisfied. It remains to verify condition (H3) of Lemma 2.1. In order to do this, let

$$
H(v, \mu):(\Omega \cap \operatorname{Ker} L) \times[0,1] \rightarrow R: H(v, \mu)=\mu(x, y)^{T}+(1-\mu) J Q N(v),
$$

where $J: \operatorname{Im} Q \rightarrow \operatorname{Ker} L$ is a linear isomorphism, $J(x, y)=(y, x)^{T}$. From assumption $\left(\mathrm{A}_{1}\right)$, we have $v^{T} H(v, \mu) \neq 0, \forall(v, \mu) \in \partial \Omega \cap \operatorname{Ker} L \times[0,1]$. Hence

$$
\begin{aligned}
\operatorname{deg}\{J Q N, \Omega \cap \operatorname{Ker} L, 0\} & =\operatorname{deg}\{H(v, 0), \Omega \cap \operatorname{Ker} L, 0\} \\
& =\operatorname{deg}\{H(v, 1), \Omega \cap \operatorname{Ker} L, 0\} \neq 0 .
\end{aligned}
$$

So, condition (H3) of Lemma 2.1 is satisfied. Therefore, by using Lemma 2.1, we see that Eq. (2.1) has a $2 k T$-periodic solution $\left(x_{k}, y_{k}\right)^{T} \in \bar{\Omega}$. Obviously, $\left(x_{k}, y_{k}\right)^{T}$ is a $2 k T$-periodic solution to Eq. (3.1) for the case of $\lambda=1$, so $\left(x_{k}, y_{k}\right)^{T} \in \Sigma$. Thus, by using Theorem 3.1, we get

$$
\left|x_{k}\right|_{0} \leq \rho_{0}, \quad\left|y_{k}\right|_{0} \leq \rho_{1}<1, \quad\left|x_{k}^{\prime}\right|_{0} \leq \rho_{2}, \quad\left|y_{k}^{\prime}\right|_{0} \leq \rho_{3} .
$$

Hence the conclusion of Theorem 3.2 holds. 
Theorem 3.3 Suppose that the conditions in Theorem 3.1 hold, then Eq. (1.1) has a nontrivial homoclinic solution.

Proof From Theorem 3.2, we see that for each $k \in \mathbf{N}$, there exists a $2 k T$-periodic solution $\left(x_{k}, y_{k}\right)^{T}$ to Eq. (2.1) with

$$
\left|x_{k}\right|_{0} \leq \rho_{0}, \quad\left|y_{k}\right|_{0} \leq \rho_{1}<1, \quad\left|x_{k}^{\prime}\right|_{0} \leq \rho_{2}, \quad\left|y_{k}^{\prime}\right|_{0} \leq \rho_{3},
$$

where $\rho_{0}, \rho_{1}, \rho_{2}, \rho_{3}$ are constants independent of $k \in \mathbf{N}$. And $x_{k}(t)$ is a solution of (1.4), so

$$
\left(\frac{x_{k}^{\prime}(t)}{\sqrt{1+\left(x_{k}^{\prime}(t)\right)^{2}}}\right)^{\prime}+c x_{k}^{\prime}(t)+f\left(x_{k}(t)\right)=p_{k}(t)
$$

which together with $y_{k}(t)=\frac{x_{k}^{\prime}(t)}{\sqrt{1+\left(x_{k}^{\prime}(t)\right)^{2}}}$ implies that $y_{k}(t)$ is continuously differentiable for $t \in R$. Also, from (3.17), we have $\left|y_{k}\right|_{0} \leq \rho_{1}<1$. It follows that $x_{k}^{\prime}(t)=\varphi\left(y_{k}(t)\right)=\frac{y_{k}(t)}{\sqrt{1-y_{k}^{2}(t)}}$ is continuously differentiable for $t \in R$, i.e.,

$$
x_{k}^{\prime \prime}(t)=\frac{y_{k}^{\prime}(t)}{\left(1-y_{k}^{2}(t)\right)^{3 / 2}} .
$$

By using (3.17) again, we have

$$
\left|x_{k}^{\prime \prime}\right|_{0} \leq \frac{\rho_{3}}{\sqrt{1-\rho_{1}^{2}}}:=\rho_{4}
$$

Clearly, $\rho_{4}$ is a constant independent of $k \in \mathbf{N}$. By using Lemma 2.3, we see that there is a function $x_{0} \in C^{1}(R, R)$ such that for each interval $[a, b] \subset R$, there is a subsequence $\left\{x_{k_{j}}\right\}$ of $\left\{x_{k}\right\}_{k \in \mathbf{N}}$ with $x_{k_{j}}^{\prime}(t) \rightarrow x_{0}^{\prime}(t)$ uniformly on $[a, b]$. Below we show that $x_{0}(t)$ is just a homoclinic solution to Eq. (1.1).

For all $a, b \in R$ with $a<b$, there must be a positive integer $j_{0}$ such that for $j>j_{0}$, $\left[-k_{j} T, k_{j} T-\varepsilon_{0}\right] \supset[a-\alpha, b+\alpha]$. So, for $j>j_{0}$, from (1.5) and (3.18) we see that

$$
\left(\frac{x_{k_{j}}^{\prime}(t)}{\sqrt{1+\left(x_{k_{j}}^{\prime}(t)\right)^{2}}}\right)^{\prime}+c x_{k_{j}}^{\prime}(t)+f\left(x_{k_{j}}(t)\right)=p(t), \quad t \in[a, b],
$$

which results in

$$
\begin{aligned}
\left(\frac{x_{k_{j}}^{\prime}(t)}{\sqrt{1+\left(x_{k_{j}}^{\prime}(t)\right)^{2}}}\right)^{\prime} & =-c x_{k_{j}}^{\prime}(t)-f\left(x_{k_{j}}(t)\right)+p(t) \\
& \rightarrow-c x_{0}^{\prime}(t)-f\left(x_{0}(t)\right)+p(t) \quad \text { uniformly on }[a, b] .
\end{aligned}
$$

Since $\frac{x_{k_{j}}^{\prime}(t)}{\sqrt{1+\left(x_{k_{j}}(t)\right)^{2}}} \rightarrow \frac{x_{0}^{\prime}(t)}{\sqrt{1+\left(x_{0}^{\prime}(t)\right)^{2}}}$ uniformly for $t \in[a, b]$ and $\frac{x_{k_{j}}^{\prime}(t)}{\sqrt{1+\left(x_{k_{j}}(t)\right)^{2}}}$ is continuous differentiable for $t \in(a, b)$, we have

$$
\left(\frac{x_{0}^{\prime}(t)}{\sqrt{1+\left(x_{0}^{\prime}(t)\right)^{2}}}\right)^{\prime}=-c x_{0}^{\prime}(t)-f\left(x_{0}(t)\right)+p(t), \quad t \in(a, b) .
$$


Considering that $a, b$ are two arbitrary constants with $a<b$, it is easy to see that $x_{0}(t)$, $t \in R$ is a solution to system (1.1).

Now, we will prove $x_{0}(t) \rightarrow 0$ and $x_{0}^{\prime}(t) \rightarrow 0$ as $|t| \rightarrow \infty$. Since

$$
\begin{aligned}
\int_{-\infty}^{+\infty}\left(\left|x_{0}(t)\right|^{p}+\left|x_{0}^{\prime}(t)\right|^{2}\right) d t & =\lim _{i \rightarrow+\infty} \int_{-i T}^{i T}\left(\left|x_{0}(t)\right|^{p}+\left|x_{0}^{\prime}(t)\right|^{2}\right) d t \\
& =\lim _{i \rightarrow+\infty} \lim _{j \rightarrow+\infty} \int_{-i T}^{i T}\left(\left|x_{k_{j}}(t)\right|^{p}+\left|x_{k_{j}}^{\prime}(t)\right|^{2}\right) d t .
\end{aligned}
$$

Clearly, for every $i \in N$ if $k_{j}>i$, then by (3.3) and (3.7),

$$
\int_{-i T}^{i T}\left(\left|x_{k_{j}}(t)\right|^{p}+\left|x_{k_{j}}^{\prime}(t)\right|^{2}\right) d t \leq \int_{-k_{j} T}^{k_{j} T}\left(\left|x_{k_{j}}(t)\right|^{p}+\left|x_{k_{j}}^{\prime}(t)\right|^{2}\right) d t \leq d_{0}^{2}+d_{1}^{p} .
$$

Let $i \rightarrow+\infty$ and $j \rightarrow+\infty$; we have

$$
\int_{-\infty}^{+\infty}\left(\left|x_{0}(t)\right|^{p}+\left|x_{0}^{\prime}(t)\right|^{2}\right) d t \leq d_{0}^{2}+d_{1}^{p}
$$

and then

$$
\int_{|t| \geq r}\left(\left|x_{0}(t)\right|^{p}+\left|x_{0}^{\prime}(t)\right|^{2}\right) d t \rightarrow 0
$$

as $r \rightarrow+\infty$. So, by using Lemma 2.2 as $|t| \rightarrow+\infty$, we obtain

$$
\begin{aligned}
\left|x_{0}(t)\right| & \leq(2 T)^{-\frac{1}{p}}\left(\int_{t-T}^{t+T}|x(s)|^{p} d s\right)^{\frac{1}{p}}+T(2 T)^{-\frac{1}{2}}\left(\int_{t-T}^{t+T}\left|x^{\prime}(s)\right|^{2} d s\right)^{\frac{1}{2}} \\
& \leq\left[(2 T)^{-\frac{1}{p}}+T(2 T)^{-\frac{1}{2}}\right]\left(\int_{t-T}^{t+T}|x(s)|^{p} d s+\int_{t-T}^{t+T}\left|x^{\prime}(s)\right|^{2} d s\right)^{\min \left\{\frac{1}{2}, \frac{1}{p}\right\}} \rightarrow 0 .
\end{aligned}
$$

Finally, we will show that

$$
x_{0}^{\prime}(t) \rightarrow 0 .
$$

From (3.17), we know

$$
\left|x_{0}(t)\right| \leq \rho_{0}, \quad\left|x_{0}^{\prime}(t)\right| \leq \rho_{2} \quad \text { for } t \in R \text {. }
$$

From (1.1), $\left(\mathrm{A}_{1}\right)$ and $\left(\mathrm{A}_{2}\right)$, we have

$$
\begin{aligned}
\left|\left(\frac{x_{0}^{\prime}(t)}{\sqrt{1+\left(x_{0}^{\prime}(t)\right)^{2}}}\right)^{\prime}\right| & \leq c\left|x_{0}^{\prime}(t)\right|+\left|f\left(x_{0}(t)\right)\right|+|p(t)| \\
& \leq c \rho_{2}+\sup _{x \in\left[-\rho_{0}, \rho_{0}\right]} f(x)+B:=M_{2} \quad \text { for } t \in R .
\end{aligned}
$$

If (3.23) does not hold, then there exist $\varepsilon_{1} \in\left(0, \frac{1}{4}\right)$ and a sequence $\left\{t_{k}\right\}$ such that

$$
\left|t_{1}\right|<\left|t_{2}\right|<\left|t_{3}\right|<\cdots<\left|t_{k}\right|+1<\left|t_{k+1}\right|, \quad k=1,2, \ldots
$$


and

$$
\left|x_{0}^{\prime}\left(t_{k}\right)\right| \geq \frac{2 \varepsilon_{1}}{\sqrt{1-\left(2 \varepsilon_{1}\right)^{2}}}, \quad k=1,2, \ldots
$$

From this we have, for $t \in\left[t_{k}, t_{k}+\varepsilon_{1} /\left(1+M_{2}\right)\right]$,

$$
\begin{aligned}
\left|x_{0}^{\prime}(t)\right| & \geq\left|\frac{x_{0}^{\prime}(t)}{\sqrt{1+\left(x_{0}^{\prime}(t)\right)^{2}}}\right|=\left|\frac{x_{0}^{\prime}\left(t_{k}\right)}{\sqrt{1+\left(x_{0}^{\prime}\left(t_{k}\right)\right)^{2}}}+\int_{t_{k}}^{t}\left(\frac{x_{0}^{\prime}(s)}{\sqrt{1+\left(x_{0}^{\prime}(s)\right)^{2}}}\right)^{\prime} d s\right| \\
& \geq\left|\frac{x_{0}^{\prime}\left(t_{k}\right)}{\sqrt{1+\left(x_{0}^{\prime}\left(t_{k}\right)\right)^{2}}}\right|-\int_{t_{k}}^{t}\left|\left(\frac{x_{0}^{\prime}(s)}{\sqrt{1+\left(x_{0}^{\prime}(s)\right)^{2}}}\right)^{\prime}\right| d s \\
& \geq \varepsilon_{1} .
\end{aligned}
$$

It follows that

$$
\int_{-\infty}^{+\infty}\left|x_{0}^{\prime}(t)\right|^{2} d t \geq \sum_{k=1}^{\infty} \int_{t_{k}}^{t_{k}+\frac{\varepsilon_{1}}{1+M_{2}}}\left|x_{0}^{\prime}(t)\right|^{2} d t=\infty
$$

which contradicts (3.21), thus (3.23) holds. Clearly, $x_{0}(t) \not \equiv 0$, otherwise $p(t) \equiv 0$, which contradicts assumption $\left(\mathrm{A}_{2}\right)$. Hence the conclusion of Theorem 3.3 holds.

\section{Competing interests}

The authors declare that they have no competing interests.

\section{Authors' contributions}

All authors have equally contributed to obtaining new results in this article and also read and approved the final manuscript.

\section{Author details}

${ }^{1}$ Department of Mathematics, Anhui Normal University, Wuhu, 241000, China. ${ }^{2}$ College of Mathematics and Statistics, Nanjing University of Information Science and Technology, Nanjing, China.

\section{Acknowledgements}

Research supported by the NNSF of China (No. 11271197) and the key NSF of Education Ministry of China (No. 207047).

Received: 11 June 2013 Accepted: 27 August 2013 Published: 30 Sep 2013

\section{References}

1. Bergner, M: On the Dirichlet problem for the prescribed mean curvature equation over general domains. Differ. Geom. Appl. 27, 335-343 (2009)

2. Rey, O: Heat flow for the equation of surfaces with prescribed mean curvature. Math. Ann. 297, 123-146 (1991)

3. Amster, P, Mariani, MC: The prescribed mean curvature equation for nonparametric surfaces. Nonlinear Anal. 53(4), 1069-1077 (2003)

4. Benevieri, P, do Ó, JM, de Medeiros, ES: Periodic solutions for nonlinear equations with mean curvature-like operators. Appl. Math. Lett. 20, 484-492 (2007)

5. Benevieri, $\mathrm{P}$, do Ó, JM, de Medeiros, ES: Periodic solutions for nonlinear systems with mean curvature-like operators. Nonlinear Anal. 65, 1462-1475 (2006)

6. Feng, MQ: Periodic solutions for prescribed mean curvature Liénard equation with a deviating argument. Nonlinear Anal., Real World Appl. 13, 1216-1223 (2012)

7. Li, J: Periodic solutions for prescribed mean curvature Rayleigh equation with a deviating argument. Adv. Differ. Equ. 2013, 88 (2013)

8. Li, J: Existence and uniqueness of anti-periodic solutions for prescribed mean curvature Rayleigh equations. Bound. Value Probl. 2012, 109 (2012)

9. Rabinowitz, PH: Homoclinic orbits for a class of Hamiltonian systems. Proc. R. Soc. Edinb. A 114, 33-38 (1990)

10. Lzydorek, M, Janczewska, J: Homoclinic solutions for a class of the second order Hamiltonian systems. J. Differ. Equ. 219, 375-389 (2005)

11. Tang, $\mathrm{XH}$, Xiao, L: Homoclinic solutions for ordinary $p$-Laplacian systems with a coercive potential. Nonlinear Anal. TMA 71, 1124-1322 (2009) 
12. Lu, SP: Homoclinic solutions for a class of second-order $p$-Laplacian differential systems with delay. Nonlinear Anal., Real World Appl. 12, 780-788 (2011)

13. Gaines, RE, Mawhin, JL: Coincidence Degree and Nonlinear Differential Equation. Lecture Notes in Mathematics, vol. 568. Springer, Berlin (1977)

10.1186/1687-1847-2013-279

Cite this article as: Liang and Lu: Homoclinic solutions for a kind of prescribed mean curvature Duffing-type equation. Advances in Difference Equations 2013, 2013:279

Submit your manuscript to a SpringerOpen ${ }^{\circ}$ journal and benefit from:

- Convenient online submission

- Rigorous peer review

- Immediate publication on acceptance

- Open access: articles freely available online

- High visibility within the field

- Retaining the copyright to your article

Submit your next manuscript at $>$ springeropen.com 